\title{
Quality in Action Research: Reflections for Second-Order Inquiry
}

\author{
Joel Martí \\ Centre d'Estudis Sociològics sobre la Vida Quotidiana i el Treball (QUIT) \\ Department of Sociology \\ Universitat Autònoma de Barcelona \\ e-mail: Joel.Marti@uab.cat
}

\author{
Tomás R. Villasante \\ Department of Sociology II \\ Universidad Compultense de Madrid \\ e-mail: invpar@cps.ucm.es
}

2009

The final, published version is available at Springer via http://dx.doi.org/10.1007/s11213-009-9136-x

Martí, J., \& Villasante, T. R. (2009). Quality in action research: reflections for secondorder inquiry. Systemic Practice and Action Research, 22(5), 383-396. 


\section{Quality in Action Research: Reflections for Second-Order Inquiry}

\section{Abstract:}

One of the current debates in action research concerns the quality of these practices. Up to now, many contributions have focused on defining specific criteria based on action research epistemology. This article sustains (1) that prior to dealing with these questions, it is necessary to define for what purpose and for whom we are making the evaluation; (2) that this leads us to make a distinction between different evaluation models; and (3) that the quality strategies and criteria will be different for each model. In particular, the article confronts an academic evaluation model as a form of external control over the quality of action research and an internal, participatory evaluation model as a quality strategy aimed at establishing feedback for the process. Final considerations are given about the implications of both models for academia.

\section{Key words:}

action research, quality, validity, evaluation

\section{Introduction}

In recent years, a progressive interest has been aroused in different approaches to action research $(\mathrm{AR})$, there has also been an increase in literature on the quality and validity of these practices (see Avison et al., 2001; Bradbury \& Reason 2001; Champion \& Stowell, 2003; Chandler \& Torbert, 2003; Checkland \& Holwell, 1998; Feldman, 2007; Heikkinen et al., 2007; Heron, 1996a; Hope \& Waterman, 2003; McTaggart, 1998; Reason, 2006; Torbert, 2000; Turnock \& Gibson, 2001). Many of these contributions have focused on establishing criteria for evaluating quality in AR. This text sustains that, prior to dealing with these questions, it is necessary to define for what purpose and for whom we are evaluating AR; that this leads us to draw a distinction between different evaluation models; and that the evaluation strategies and criteria will be different for each model.

The arguments sustained in the text come from both academic reflection and practices associated to postgraduate studies which teams from different universities of Spain (Autonomous University of Barcelona; Complutense University of Madrid) have been 
carrying out over the last decade. The methodological tradition that feeds these experiences and the setting around which the arguments of this article revolve is Participatory Action Research (Fals Borda 1994, 2001). In particular, we are talking about community development experiences in which participatory dialogue is the basis for developing community programmes (Villasante 2006; Villasante \& Garrido 2001). The reflections contained in this article are applicable not only to these experiences, but more extensively to all those AR approaches in which the participants are also coresearchers.

\section{What is quality in AR?}

If there is anything that current debates on quality in AR have in common, that is their clear wish to move away from the classic notions of scientific validity established by Campbell and Stanley (1963). Indeed, the same concept of "validity" is often replaced by others with no positivist connotations, such as trustworthiness (Stringer 2007), authenticity (Champion \& Stowell 2003) or quality (Reason 2006), which we will use in this text. Others, like Anderson et al. (1994) and Heron (1996b) prefer to maintain the term "validity" and redefine it.

While some researchers and practitioners deny the relevance of this debate, as they regard it to be fundamentally academic and far removed from the concerns of AR practitioners (in this respect, see the online discussion transcribed in Newman, 1999), others base their arguments on the criteria proposed for qualitative research by Lincoln and Guba (1985, Lincoln 1995). Watkins (1991), for example, adapts these criteria to AR. However, the stance of the majority is to draw an epistemological distinction between qualitative research and $A R$, and to focus on action as a key $A R$ element. This is an approach that, to a large extent, has its roots in John Dewey (1941), who opposes the classic notion of "truth" with that of "warranted assertability" understood as meaningful assertions opened to ongoing inquiry, thus raising the inseparability of knowledge and practical experience (Kandlbinder 2004, 38).

In this way, unlike the quality proposals made for qualitative research, which have tended to focus more on reports as a product (Feldman 2007, 22), the criteria introduced to AR pay special attention to the development of research practice itself, and among these, it is possible to distinguish a concern for at least five dimensions: topics (about the relevance and significance of what is discussed, and about its deep 
understanding), participants (their diversity and extension; their relations); method (relations with participants and ways of knowing); consequences (defined outcomes as well as learning and empowerment); as well as the context in which AR takes place (institutions, power, interests). Behind all these dimensions it is also possible to identify a "meta-criterion" setting for the values, ethics and professional commitments (Stevenson 2002).

Without aiming to be exhaustive, we could mention some of the contributions made in this sense. Anderson, Herr \& Nihlen (1994), conserving the term validity, introduce five criteria for AR: outcome validity (the extent to which actions occur, which leads to the resolution of the problem), process validity (method and forms of relation with the participants), democratic validity (presence of all parties at stake), catalytic validity (ability of the participants to know and transform reality) and dialogic validity (review by others). Champion \& Stowell (2003) focus on participants (their choice, the criteria for inclusion, and the reasons for non-involvement, or exclusion), engagement (about achieving commitment), authority (under which action may be taken, as it influences the degree of self-governance of participants), relationships (links between actors) and learning (reflection process and knowledge). Reason (2006), after the contributions made in Bradbury \& Reason (2001) and considering co-operative inquiry to be more of a worldview than a mere research approach, introduces four sets of questions which, with greater or lesser intensity, deal with every AR: pursuing worthwhile purposes, democracy and participation, plural ways of knowing, and emergent developmental forms. For Heron (1996b, 158) "the outcomes of a co-operative inquiry are valid if they are well-grounded in the forms of knowing -practical, propositional, presentational, experiential - which support them", and proposes sets of criteria for the validation of practice in co-operative inquiry: executive criteria (capacity to act), technical criteria (effectiveness in the achievement of goals), psychosocial criteria (whether action is free of psychological and organizational pathologies); and moral criteria (contribution to transformation) (Heron 1996a, 43).

Evaluating these criteria will, as in all scientific activity, require their explanation and critical reflection throughout the research process. In this respect, Checkland and Holwell $(1998,18)$, refer to a declared-in-advance methodology "in such a way that the process is recoverable by anyone interested in subjecting the research to critical scrutiny". And Reason (2006, 189-190) indicates in this sense that quality must be based on explaining the choices made during the research: "researchers need to be aware of the choices open to them; to make these choices clear and transparent to 
themselves, and to their inquiry partners"; in this respect, he discerns a double dimension: the internal (ability to see choices and understand their consequences) and the external (about how these choices are made transparent to the audience).

The debate on the criteria is still open and subject to future discussions. We do not aim to close the debate here, not because we share the farewell to criteriology proposed by Schwandt (1996), but because we believe -and this is the argument that is developed within this text- that questions must be asked before its concretion: a debate as to where, for what purpose and for whom the evaluation is made. And also about who makes the choices, who thinks about them and to whom they are made transparent. The following section tackles these issues.

\section{Quality for whom and for what?}

There are several reasons to justify the interest in quality in AR. Partly, the need to consolidate these research practices in the academia as a relevant (and different) form of generating knowledge. Also, the wish to debate and co-construct criteria and working methods among researchers and practitioners working in diverse contexts and frameworks. Moreover, the intention to provide feedback for the AR processes themselves. In all cases, those of us who often write and speak about the subject are "professional researchers", and we do so in academic settings, or by addressing an academic audience such as this.

Perhaps the first question to ask ourselves is for what kind of audience we are making the evaluation, since notions such as "quality" or "validity" are social constructions (Kvale 1995), and what is constructed as "valid" in academia may not necessarily coincide with what is "valid" for participants, for an institution which finances AR projects or for a researcher. Academia -or, rather, the hegemonic scientific communities that "inhabit" it- is perhaps interested in classical issues of validity and reliability ("Is it an acceptable source of knowledge under the scientific rigour? How does it fit in with reality? Is it replicable?"); perhaps the second group is more interested in their immediate application ("does it work?"); the third group may be more concerned, for example, with the perception of the participants ("Please can you measure the satisfaction of all those who have participated in the project I have financed?"); for the last group, the most important aspect may be learning and the ability to influence that is generated by the entire process by the different actors ("what 
about skills and empowerment?") -which Lather (1986) and Anderson et al. (1994) refer to as "catalytic validity". The debate on quality is not an analytical or technical question, but above all a normative and political one.

Bradbury and Reason $(2001,454)$ say that "in participative inquiry, which has emerged in its fullest sense as not with people but research by people, responsibility for exploring these issues [about quality] will rest with the community as a whole" (and we could add to this argument: because it is research not only done by people, but also for people). That is, it lies in the very epistemological foundation of AR which, irrespective of the fact that "others" want to evaluate it, is also evaluated by and for participants. And, given that in participatory action research, the individuals/actors involved not only form a part of the research context, but are immersed in it, and therefore co-construct the research process and its results, it seems relevant for the criteria and evaluation methods to be co-defined in each case with the participants.

Associated with "for whom" AR is evaluated is "for what purpose". A researcher or practitioner may simply ask him/herself, "Am I doing a good job?", and ask the participants or the academic community this same question. It is a question that is appropriate and necessary, for example, in being accountable to participants, or in a dissertation submitted to the academic community, and evokes a more "traditional" idea of research evaluation, research being understood as control -which Reason $(2006,191)$ calls "a form of policing research" and Kvale $(1995,36$, cited in Reason, 2006, 191), from a post-modern approach, refers to as "an expression of a modern legitimation mania".

However, the epistemological interest of AR is also present -above all- in other fields. If its horizons involve the co-generation of knowledge and promoting change in social practices, then the debate on "quality" is not only about "control", but also a component part of the AR process that provides feedback for knowledge and action generated through learning. Nothing is closer to Kurt Lewin's classic spiral design: (a) quality as a process of self-reflection and co-construction of knowledge -for improving theory; (b) quality as an ongoing improvement strategy in the management of a process -for improving action. In this case, we are referring to evaluation aimed at the improvement or transformation of practice, based on learning arising from reflection about the process. 
Another purpose that may stem from evaluation is that the analysis of practices serves to allow them to be applied beyond the local setting under study. Methodological conceptualizations of this criterion involve external validity (Campbell \& Stanley 1963), naturalistic generalization (Stake 1994), transferability (Lincoln \& Guba 1985) or transcontextual credibility (Greenwood \& Levin, 1998). Academics will often show interest in these issues, but not only them; participants may also be interested in evaluating not only the practice in which they are immersed, but also other practices, in order to ascertain what is working, what conflicts are being detected, what potentialities and threats are identified and be able to "transfer" this knowledge to their own practices. In these cases, the evaluation will also be required to have some form of transferability that enables what has been learned to be applied to other settings.

We can classify this distinction between the different "whys" of evaluation (such as control, learning or transferable knowledge) into two dimensions, as shown in Figure 1, in such a way that four quadrants show different concepts of $A R$ evaluation. Furthermore, each of the quadrants is usually closer to different "audiences" of the evaluation, or put another way, different actors tend to conceive the evaluation based on different purposes. In the first quadrant $(A)$, we find forms of self-evaluation that are oriented towards participants that raise the question of considering quality as a feedback of the process itself, and without intending to generate knowledge beyond the local setting: the evaluation is learning "for us" and "for our practice", and the driving force that transforms it. In the second quadrant $(B)$, there are evaluations that also have no aim of transferability, and which understand quality as a way of controlling "good work" and the results thereof; these include, for example, evaluations made by external agencies and institutions which sometimes finance local AR projects and require local actors to be accountable. In the third quadrant $(C)$ we can identify forms of evaluation that promote the exchange of experiences (through the analysis of "best practices" and similar), so that the learning arising from this analysis can be transferred and applied in other contexts. Lastly, in D, we find academic, external forms of evaluation: "quality control" in a practice -a 'research' practice- in order to produce base knowledge that is placed on a higher level of abstraction and can be applied beyond the local setting. Of course, we are referring to general types, and other forms of evaluation are possible. For example, an external evaluation may be requested by the actors in the local setting (for "verifying" compliance of objectives). On the contrary, evaluations promoted by external agencies may give priority to internal, formative types of evaluation. 


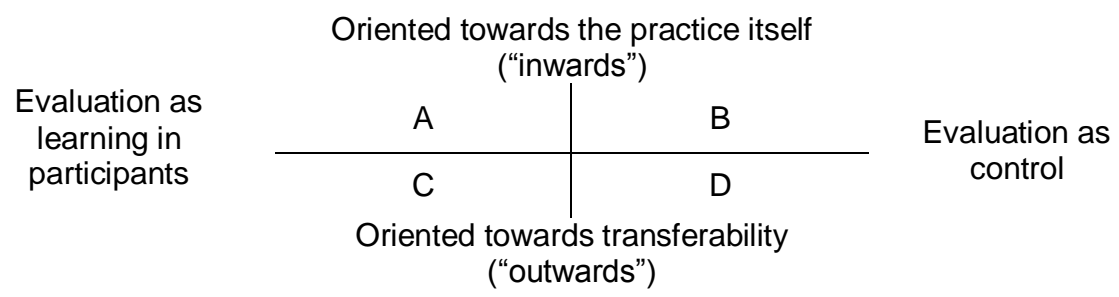

Fig. 1 Purposes and concepts of evaluation

In this text we will focus more specifically on two models that are situated in the first $(A)$ and fourth (D) quadrants. One broaches the subject of an internal evaluation, aimed at providing feedback for the AR social relations process itself, and the other, on the contrary, refers to an "academic validation" understood as external control of a form of producing knowledge/action.

This text sustains that, above and beyond evaluation understood as a "hallmark of quality", it is important to focus on it as an opportunity to make progress in each AR practice, and be able to distinguish one form of evaluation from another, because even though they are known by the same name, they are different things. On the other hand, this argument does not question the need to establish forms of evaluation and quality criteria that make AR more "defensible and potentially transferable" (Checkland \& Holwell 1998, 9). As a bridge between social practice and scientific activity, AR requires this dialogue with academia, since it feeds off its theoretical and methodological reflections.

Figure 2 shows each model in more detail.

\begin{tabular}{|c|c|c|}
\hline & AR academic evaluation & AR internal evaluation \\
\hline $\begin{array}{l}\text { Audience } \\
\text { (for whom) }\end{array}$ & $\begin{array}{l}\text { Academics, scientific } \\
\text { community }\end{array}$ & Participants and local actors \\
\hline $\begin{array}{l}\text { Purpose } \\
\text { (for what) }\end{array}$ & $\begin{array}{l}\text { "Quality control" } \\
\text { "Outwards" evaluation } \\
\text { (transferability) }\end{array}$ & $\begin{array}{l}\text { Feedback: learning, } \\
\text { improvement/transformation } \\
\text { "Inwards" evaluation }\end{array}$ \\
\hline $\begin{array}{l}\text { What is being } \\
\text { evaluated }\end{array}$ & AR Design & Social practice as a whole \\
\hline Positionality & External & Internal \\
\hline Orientation & $\begin{array}{l}\text { Result-oriented (findings) } \\
\text { Ex post evaluation }\end{array}$ & $\begin{array}{l}\text { Process-oriented (social relation) } \\
\text { Ongoing evaluation }\end{array}$ \\
\hline Scope & $\begin{array}{l}\text { Contribution to base knowledge } \\
\text { Public knowledge }\end{array}$ & $\begin{array}{l}\text { Incidence in local setting } \\
\text { Local knowledge and practice }\end{array}$ \\
\hline
\end{tabular}

Fig. 2 Internal and academic model of quality evaluation in Action Research 
The argument defended here is that these two general models have different concepts of quality and therefore require different approaches. The preceding sections have already dealt with two basic aspects of this difference (the audience and the purposes of the evaluation), and we will now indicate other aspects that define them -taking the contributions of Herr and Anderson (2005), regarding the implications of doing doctoral dissertations on AR projects, as a starting point.

What is being evaluated: As stated by Herr \& Anderson $(2005,89)$, one of the main differences between the academic analysis of an AR process and the process itself is that the first of these is an individual task while the second is a collective one. The academic evaluation is aimed at judging the knowledge process carried out by the researcher. And the criteria on which this judgement is made are oriented at evaluating the relevance of the knowledge produced in relation to the social reality being studied. If "anything fails" there, it is not reality but the research process, and therefore the researcher: "his/her" theories, "his/her" methods, "his/her" interpretations. However, in $A R$, this distinction (between the studied reality, the knowledge process and the researcher) is more complex: as already mentioned above, the individuals/actors involved not only form a part of the research context, but are in fact involved in the method itself, and are thus co-researchers. When evaluating an AR project "from inside" and "inwards", not only is the researcher's work being judged, but also a context and a social process in which the actors, situated in an action frame, design strategies in relation to that process: their learning, empowerment or the type of change produced will also depend, in particular, on them and on the conditioning factors of the setting. In academic evaluation, all these aspects form a part of the "context of study", but are not the "object of the evaluation": what is being evaluated in this case are the decisions made by the researcher(s)/practitioner(s) in a determined context, and the way in which these decisions contribute to tackling certain quality criteria. In short: the quality of a social process is not the same as the quality of research design, even if this design is aimed at promoting a social process.

Positionality. Academic evaluation requires the "validation" of knowledge production to be sanctioned outside its construction process. Even in the most participatory approaches to research, when evaluation is defended in an academic setting (within the scope of a dissertation, or the double-blind review system of refereed journals), the distances between the "object of the evaluation", the "defender/s" and the "reviewers/examiners" will be clearly marked. On the contrary, the evaluation of an AR process aimed at learning in terms of providing feedback for the practice itself seems 
especially relevant for internal forms of evaluation. In these forms of evaluation, the roles of the "evaluator" and the "evaluated" merge, and the evaluation process is within the same social practice.

Orientation. Academic research is aimed at producing base knowledge of a studied topic. A product is obtained (findings), and the process through which this is obtained is judged with respect to the appropriate means used to obtain that result. This approach clashes with AR epistemology in that (a) the social relations process produced through the research is just as important as the results obtained; and (b) both the process and the results are not only oriented at producing knowledge, but also at social practice as two inseparable dimensions (Herr \& Anderson 2005, 86). Therefore, the aspects referring to the process, social relations and action may -and should- be analysed on the basis of academic evaluation. However, whereas an evaluation that is intended to provide feedback to the process "from inside" will analyse these aspects in the course of the process itself, academic evaluation will do so based on an ex-post orientation, and observing the action related to the AR design.

Scope. Academics may show a certain amount of sympathy for AR when social theory and methodology is used as a form of local knowledge oriented at producing changes in local settings. However, doubts and objections emerge when this work is presented as a way of producing knowledge beyond the setting: AR is often seen to be something practitioners do, while academic researchers do basic research (McTaggart 1998, 213; Herr \& Anderson 2005, 52). In this context, the distinction made by Cochran-Smith \& Lytle (1993, cited in Herr and Anderson, 2005, 6) between local knowledge and public knowledge is useful. An AR process may be evaluated based on its capacity to face local challenges from the production of local knowledge. But it can also be evaluated based on its capacity to produce knowledge about these same issues at a higher level of abstraction than the analysed setting, and consequently, based on its capacity to produce formal theory. Both aspects are closely related, but the second case will require specific reflection about the transferability (Lincoln \& Guba, 1985) or transcontextual credibility (Greenwood \& Levin, 1998) of these practices.

\section{Evaluating quality from second-order processes: design and criteria}

Elliot (1991) makes a distinction between a first-order process of AR (about social problems being studied) and a second-order inquiry (focused on analysing the 
experience of facilitators, and the implications and consequences of their relations with others). Starting with this distinction, we understand AR evaluation as a second-order process that involves analysing the link between the first-order AR design and the social practice to which it belongs. A second-order inquiry that, as stated by Losito, Pozzo \& Somekh (1998), not only concerns external researchers but it also applies to all those participants who are inside action research groups.

From this approach, and based on the previous reflections, in this section we deal with some considerations regarding the design of both evaluation models presented. In each of the models, we will pay special attention to three aspects: the relationship between the first-order and the second-order processes; the relationships between participants and practitioners/researchers; and the implications of all this when defining the evaluation criteria.

\subsection{Academic evaluation of $A R$}

The external evaluation model, and in particular, the academic evaluation of AR may be expressed by returning to and adapting the schema proposed by Zuber-Skerritt and Fletcher (2007). Basing their reflections on the performing of action research thesis in social sciences, these authors make a distinction between a primary process (which they refer to as the core action research) and a secondary process (the performing and writing of an academic work on the core process). Whereas the former generates social relations among the participants, the latter observes 'from outside' the nature and dynamics of these relations, and evaluates them in relation to certain quality criteria, in order to produce a "product" of a different nature: an academic analysis regarding its quality.

Adapting this proposal made by the foregoing authors, this idea can be expressed through the attached figure. The core AR constitutes the fieldwork for a second-order analysis that will lead to an academic evaluation. This, in turn, will validate the production of base knowledge about the social practices studied and provide feedback for further research. 


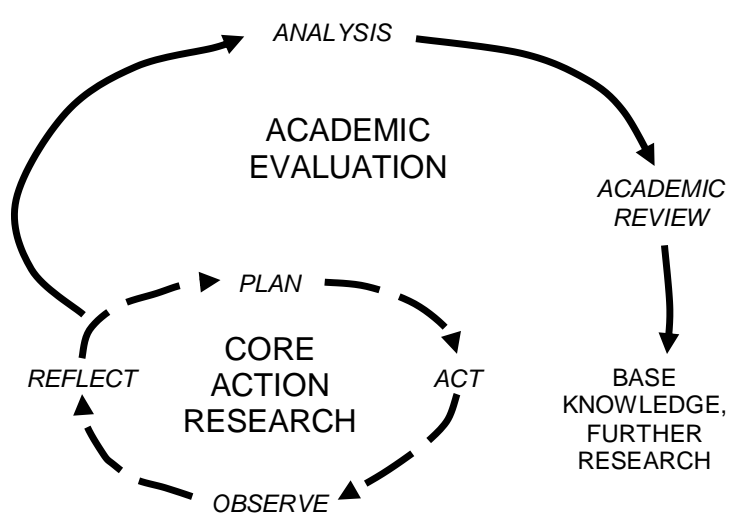

Fig. 3 Core Action Research and Academic Evaluation

Source: Own diagram, adapting a schema by Zuber-Skerritt \& Fletcher $(2007,421)$

In the academic evaluation process, in the strictest sense, participants placed in the first-order process (core AR) are mere objects of research (even in the case of the evaluation being carried out by local practitioners, these practitioners must establish a clear separation between the two orders). However, this external evaluation allows feedback to be introduced, that of returning towards the core process in which academic reflection/evaluation returns to the community/organisation itself. Some experiences carried out in Catalonia (Spain) show that this feedback contributes to significant improvements in local practices: from an external, academic approach, Castellà \& Jorba (2005) carried out an ex post evaluation of local citizen participation projects, whose results were returned and discussed with local practitioners. This debate helped them not only to reflect on their own work, but also to improve further practices. Thus, feedback from academia to local practices places external evaluation at an interesting point between quadrant $D$ and quadrant $A$; in section 5 further considerations will be made on this issue.

Regarding the quality criteria, in this model they are an academic construction, since the second-order process is detached from the AR practice itself, which becomes an external object of analysis. However, the concretion of these criteria, which is external, can be also dependent on the practice that is being evaluated; as Reason says (2006, 198-199), sometimes immediate practical outcome is most important; in other practices priority will be given to the incorporation of weaker voices; and in others to an in-depth exploration of values. However, in conceptual terms, they are two different agendas: that of academic research and that of AR practice. For even in the case of the criteria being the same, the way in which they are dealt with will be different in each context: 
as a "finding" and "arrival point" as opposed to a "process" and "spiral", as a "sanction" as opposed to as a "catalyst".

\subsection{Internal, participatory evaluation of $A R$ : From quality of $A R$ to quality for $A R$}

The design and development of evaluation is, in this case, within the AR spiral itself, which involves participatory, continuous analysis and reflection. Participatory in that the participants define the object of the evaluation and the criteria to be evaluated (which, in turn, leads to collective reflection on the objectives of the process as a whole). It is also participatory since the participants themselves issues value judgements and define strategies with respect to them. And continuous, because it permits the process to be "recreated" during its development (evaluation is a "starting point" rather than an "arrival point"). In this model of "AR on AR", evaluation is a process of social relation between the participants and hence, provides "in process" learning and feedback during all its phases.

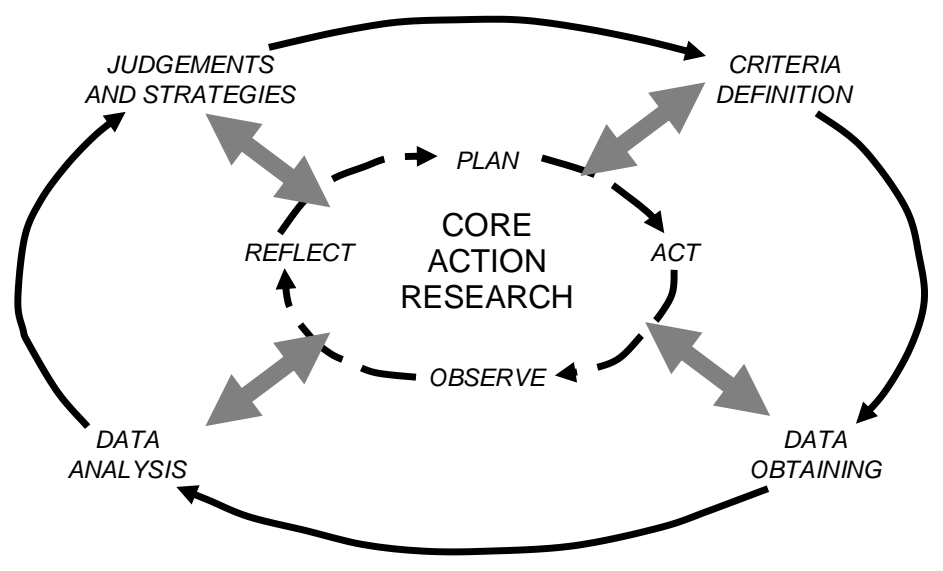

Fig. 4 Participatory Evaluation of AR as a second-order process.

The epistemology of AR itself is obviously a point of reference for this process of selfreflection on quality, in the same way as current approaches in qualitative and participant evaluation that are based in some way or other on the contributions of Guba \& Lincoln (1981), Patton $(1981,2002)$ or Stake (1975) may also contribute to this debate. What these approaches have in common is that firstly, they incorporate participants into the evaluation process and secondly, they design strategies for research and reflection that are specially aimed at producing knowledge of the development of the process that will enable feedback, and also allow the actors to carry it out. 
Thus, in this case, the second-order process is integrated into the first-order one, and both participants and practitioners/researchers are research subjects that enter into dialogue about the purposes, methods and results of the evaluation. The role of each party in this dialogue will be different, not only due to each local setting, but also to each AR tradition and evaluation approach: thus, O'Sullivan (2004, 8-9) describes how for some approaches, the participants must lead the evaluations (Fetterman 2001; Patton 2002), whereas others defend a more active role of the "professional evaluators" (Cousins \& Earl 1995; O'Sullivan \& O'Sullivan 1998). This debate does, in fact, reflect tension between different dimensions of evaluation (as learning vs as control; inwards vs outwards) and has been extremely creative in community development experiences carried out in Spain. While some practices close in on themselves, breaking all links with "others" (with the university, with other local practices) and end up "dying of success", the experiences that have been more rewarding and innovative are those that have maintained an interrelation between internal and external reflection (e. g. with the university and/or with other local practices). Through this interrelation, internal, participatory evaluation, which we have placed in quadrant $A$, is intersected with $B, C$ and $D$, i.e., it receives feedback from other evaluation approaches but without losing sight of its focus on A. We will come back to this in the next section.

In all these cases, quality criteria are a local construction which involves dialogue with others. On the one hand, it involves dialogue among participants -because, as has already been said, defining criteria is not merely a technical issue, but also a political issue, and this definition involves the existing interests, conflicts and power relations within the setting. On the other, it involves dialogue between participants and researchers/practitioners -since it implies synergies between practical knowledge and theoretic/methodological knowledge.

Based on our previous work in Spain and on a recent project of Citizenship School in Chile, we believe that there are two principles that help to define evaluation criteria that are useful to feedback processes in terms of the participants' learning as well as their capacity to transform: transduction and stimulation.

With the transduction concept that we have introduced in other texts (Villasante 2006) we are referring to a strategy that goes beyond, on the one hand, the rigidity of the deductive dynamics of analysis and evaluation (with an a priori imposition of abstract 
theories and criteria that the participants may consider to be confining), and, on the other hand, the limitation to building up transforming practices based on criteria and conceptualisations anchored in daily routines. Transduction is, to us, a dynamic that is at once relational, reflective and performative and which, by introducing analysers (Lapassade 1971), tries to a) promote creative situations in the relationships between participants and local networks, b) carry out collective reflections in order to generate new knowledge, and c) plan transformative actions based on these movements and reflections. In this sense, the transductive dynamic connects with John Heron's approach to validity in co-operative inquiry (Heron 1996b), and in particular his emphasis on relational issues as a way to overcome "uncritical subjectivity".

Secondly, we believe that the evaluation's transforming potential is achieved through the construction of criteria that are "stimulating" for the actors themselves so that these easily see the direction for improvement. The idea of "stimulation" arises as a response to the attitudes frequently shown by participants towards evaluations: fear of exposing oneself to others, resistance to a demand from an external instutition, or simply, tedium when faced with tasks that are considered to be a mere administrative requirement. From a "stimulating" approach, the question is not so much "what the goal is and how we will evaluate its achievement" but rather "what we can evaluate so that it motivates us to make an improvement in this regard" and "how we involve ourselves in this". We believe that this motivating, dynamising aspect is very important for those people who involve themselves in the process of change, whether they are professionals or volunteers.

\section{Conclusion: Intersections between models and symmetries between actors}

In this text, it has been argued that the evaluation of quality in AR may be conceived on the basis of different approaches, and this has implications for both the way it is applied and for defining the criteria to be evaluated. In particular, two questions have been introduced on which the quality debate can be based (its purposes and its audience) and two evaluation models of AR have been compared; academic evaluation as a form of external control and internal, participatory evaluation as a form of providing learning and change for the process. In this section, we shall make some considerations on the contributions and challenges of these models and on intersections between them. 
The first model presented involves taking dialogue on $A R$ to the academic field, a dialogue that is important in two respects. Firstly, for AR itself, since it promotes external methodological and epistemological reflection beyond the local settings. Secondly, for academia as a whole: by "defending" these practices in the university, AR challenges other methodologies as a way of producing base knowledge (Herr \& Anderson 2005, 128). This challenge is not a purely methodological debate, as it entails overcoming resistance to change by the university institution itself. As Greenwood $(2007,259)$ points out:

"Institutions like mine do not oppress or prohibit AR intentionally. Rather, they are unable to see the value of $A R$ as an approach to addressing their most pressing internal and external problems and they do not yet feel urgent enough about threats to their survival to try to learn anything they do not already know"

Furthermore, in this model the relation between academia and AR not only deals with the production of scientific knowledge, but also with how the university returns this knowledge to social practices. In this regard, feedback to AR projects was introduced, as an intersection between quadrants D-A. However, this intersection is asymmetrical since it is the university that lays down the rules of the game (Martí 2008, 44): criteria, methods and results are defined without the participants.

The second model presented (internal, participatory evaluation of AR) transfers the dialogue to another field: movements, institutions and participants are the agents that define what it is and not quality and what they want to do with it. In this regard, the theoretical and methodological knowledge that practitioners and researchers may provide is made available to local actors.

However, here, as in the first model, the dialogue is not symmetrical because the rules of the game (and the definition of the quality criteria as part of them) stem from the power relations that define the field. Thus, in the same way as Herr and Anderson $(2005,101)$ warn about the risks of external researchers imposing the agenda on participative research based on their own academic priorities, in this model we must take into account the perversions of the agenda being imposed by participants (or groups of participants) in a setting of power and conflict.

In this sense, it seems relevant to think of more symmetrical spaces of relation between the academic reflection and local practices. Symmetrical spaces based on the 
autonomy of each party, to discuss and transform practices. But to do this, academia must be able to go beyond quadrant $D$ which, to our minds, poses two challenges.

The first challenge is going from conceiving knowledge as something that must be "controlled" to conceiving it as a tool for learning and practice among people and organizations. This renunciation of control has some implications. Firstly, the recognition of non-academic sources of knowledge and its potential to generate a better understanding of reality in synergy with scientific inquiry. Secondly, and linked to the previous point, academia's commitment to local practices from a relationship of true equality and exchange with the other actors, that is to say, giving up a sometimes "paternalist", if not "advisory" role. It also involves reflecting on and making clear the interests that guide the different parties in an AR process (universities, public administrations and stakeholders, participants), the recognition of the power relations among actors and, based on this recognition, the shared will to create consensus.

The second challenge for academia is conceiving knowledge not only as the analysis of the present but also as a generator of possible futures. We think that the contribution of Santos (2002, 2003) regarding the "sociology of emergencies" may shed considerable light in this respect. For Santos, reality must be considered as a field of not only experience but also possibility and, within this context, the role of critical analysis consists of exploring the nature and the range of alternatives to that which is empirically given (Santos 2003, 23).

We believe that it is within this context where the key AR issues and their evaluation can be carried out more fully. 


\section{References}

Anderson, G. L.; Herr, K., and Nihlen, A. S. (1994). Studying Your Own School: An Educator's Guide to Qualitative Practitioner Research, Sage, Thousand Oaks, CA.

Avison, D.; Baskerville, R., and Myers, M. (2001). Controlling action research projects. Inform. Tech. \& People, 14(1), 28-45.

Bradbury, H., and Reason, P. (2001). Conclusion: broadening the bandwidth of validity: Issues and choice-points for improving the quality of action research. In Reason, P. and Bradbury, H. (eds.), Handbook of Action Research: Participatory Inquiry and Practice, Sage, London, pp. 447-455.

Campbell, D. T., and Stanley, J. C. (1963): Experimental and quasi-experimental designs for research on teaching. In Gage, N. L., (ed.), Handbook of Research on Teaching, Rand McNally, Chicago, pp. 171-246.

Castellà, C., and Jorba, L. (2005). Evaluación de las experiencias participativas en la gestión local de Cataluña: potencialidades y amenazas. Gestión y análisis de políticas publicas, 32, 79-100.

Champion, D. and Stowell, F. (2003). Validating Action Research Field Studies: PEArL. Syst. Pract. Act. Res., 16(1), 21-36.

Chandler, D., and Torbert, B. (2003). Transforming inquiry and action by interweaving 27 flavors of action research. Action Res., 1(2), 133-152.

Checkland, P., and Holwell, S. (1998). Action research: Its nature and validity. Syst. Pract. Act. Res., 11(1), 9-21.

Cochran-Smith, M., and Lytle, S. (1993). Inside/Outside: Teacher Research and Knowledge, Teachers College Press, New York.

Cousins, J. B., and Earl, L. M. (1995). Participatory Evaluation in Education: Studies of Evaluation Use and Organizational Learning. Falmer, London.

Dewey, J. (1941). Propositions, Warranted Assertibility and Truth. The Journal of Philosophy, 38(7), 169-186.

Elliot, J. (1991). Action Research for Educational Change, Open University Press, Philadelphia.

Fals Borda, O. (1994). El problema de cómo investigar la realidad para transformarla por la praxis, Tercer Mundo, Bogotá.

Fals Borda, O. (2001). Participatory (action) research in social theory: Origins and challenges. In Reason, P. and Bradbury, H. (eds.), Handbook of Action Research: Participative Inquiry and Practice, Sage, Thousand Oaks, CA, pp. 27-37.

Feldman, A. (2007). Validity and quality in action research. Educ. Act. Res., 15(1), 21-32.

Fetterman, D. M. (2001). Foundation of Empowerment Evaluation, Sage, Thousand Oaks, CA.

Greenwood, D. J. (2007). Teaching/learning action research requires fundamental reforms in public higher education, Action Res., 5(3), 249-264.

Greenwood, D. J., and Levin, M. (1998). Introduction to Action Research: Social Research for Social Change, Sage, Thousand Oaks, CA. 
Guba, E. G.; Lincoln, Y. S. (1981). Effective Evaluation: Improving the Usefulness of Evaluation Results through Responsive and Naturalistic Approaches, Jossey-Bass, San Francisco.

Heikkinen, H. L. T.; Huttunen, R., and Syrjälä, L. (2007). Action research as narrative: Five principles for validation. Educ. Act. Res, 15(1), 5-19.

Heron, J. (1996a). Quality as primacy of the practical. Qual. Inq., 2(1), 41-56.

Heron, J. (1996b). Co-Operative Inquiry: Research into the Human Condition. Sage, London.

Herr, K., and Anderson, G. L. (2005). The Action Research Dissertation: A Guide for Students and Faculty, Sage, Thousand Oaks, CA.

Hope, K. W., and Waterman, H. A. (2003). Praiseworthy pragmatism? Validity and action research. Journal Adv. Nurs., 44(2), 120-127.

Kandlbinder, P. (2004). Reconstructing educational technology: A critical analysis of online teaching and learning in the university. Unpublished doctoral thesis. University of Sydney, Sydney.

Kvale, S. (1995). The social construction of validity. Qual. Inq., 1(1), 19-40.

Lapassade, G. (1971). L'Analyseur et l'Analyste. Gauthiers-Villars, Paris.

Lather, P. (1986) Issues of validity in openly ideological research: between a rock and a hard place. Interchange, 17:63-84.

Lincoln, Y. (1995). Emerging criteria for quality in qualitative and interpretive research. Qual. Inq., 1(3), 275-289.

Lincoln, Y., and Guba, E. (1985). Naturalistic Inquiry, Sage, Thousand Oaks, CA.

Losito, B., Pozzo, G., and Somekh, B. (1998). Exploring the labyrinth of first and second order inquiry in action research. Educ. Action Res. 6(2), 219-240.

Martí, J. (2008). From Local Practices to Public Knowledge: Action Research as Scientific Contribution. Review Essay [online]. Forum Qual. Soc. Res., 9(2), art. 2. Available at http://nbn-resolving.de/urn:nbn:de:0114-fqs080320 [Date of access: November 10, 2008].

McTaggart, R. (1998). Is validity really an issue for participatory action research? Cult. and Organ., 4(2), 211-236.

O'Sullivan, R. G. (2004). Practicing Evaluation: A Collaborative Approach, Sage, Thousand Oaks, CA.

O'Sullivan, R. G., and O'Sullivan, J. M. (1998). Evaluation voices: Promoting evaluation from within programs through collaboration. Evaluation and Program Planning, 21(1), 21-29.

Patton, M. Q. (1981). Practical Evaluation, Sage, Newbury Park, CA.

Patton, M. Q. (2002). Qualitative Research and Evaluation Methods (3rd ed.), Sage, Thousand Oaks, CA.

Reason, P. (2006). Choice and quality in action research practice. J. Manage. Inq., 6(15), 187203.

Santos, B. S. (2002). Para uma sociologia das ausências e uma sociologia das emergências. Revista Crítica de Ciências Sociais, 63, 237-280. 
Santos, B. S. (2003). Crítica de la razón indolente. Contra el desperdicio de la experiencia. Desclée de Brouwer, Bilbao.

Schwandt, T. A. (1996). Farewell to Criteriology. Qual. Inq., 2(1), 58-72.

Stake, R. (1994). Case studies. In Denzin, N. K. and Lincoln Y. S. (eds.), Handbook of Qualitative Research, Sage, Thousand Oaks, CA, pp. 236-247.

Stake, R. (Ed.), (1975). Evaluating the Arts in Education: A Responsive Approach, Merrill, Columbus, $\mathrm{OH}$

Stevenson, R. B. (2002). Judging the Quality of Participatory Action Research. Paper presented at ISA Conference, Brisbane, Australia.

Stringer, E. T. (2007). Action Research ( $3^{\text {rd }}$ edition), Sage, Thousand Oaks, CA.

Torbert, W. R. (2000). Transforming social science: Integrating quantitative, qualitative, and action research. In Sherman, F. and Torbert, W. R. (eds.), Transforming Social Inquiry, Transforming Social Action, Kluwer, Boston, MA, pp. 67-92.

Turnock, C. and Gibson, V. (2001). Validity in action research: A discussion on theorethical and practice issues encountered whilst using observation to collect data. Journal Adv. Nurs., 36(3), 471-477.

Villasante, T. R. (2006). Desbordes creativos, Los Libros de la Catarata, Madrid.

Villasante, T. R. and Garrido, J. (2001). Methodologies for the participant construction of knowledge. Syst Pract Act Res, 14(4), 483-493.

Watkins, K. E. (1991). Validity in action research. Paper presented at the Annual Meeting of the American Educational Research Association (Chicago, IL, April 3-7 1991).

Zuber-Skerritt, O. and Fletcher, M. (2007). The quality of an action research thesis in social sciences. Qual. Assur. Educ., (15)4, 413-436. 